\title{
AUDIODESCRIÇÃO: TECENDO RELAÇÕES ENTRE A ARTE CINEMATTOGRÁFICA, TEATRAL E A DANÇA
}

\author{
Audiodescription: structuring relations between a art cinematographic, theatral and \\ dance
}

\section{Audiodescripción: tecendo relaciones entre el arte cinematográfico, teatral y la danza}

\author{
Eliana Lúcia Ferreira * \\ Gislaine de Fátima Ferreira da Silva ${ }^{* *}$ \\ Janine Lopes Carvalho *** \\ Thyara Fiorillo Duarte Resende ${ }^{* * * *}$
}

\begin{abstract}
Resumo
O artigo em tela, idealizado pelo Núcleo de Pesquisa em Inclusão, Movimento e Ensino a Distância NGIME, foi desenvolvido mediante análise dos trabalhos de conclusão de curso apresentados como pré-requisitos para obtenção de título de pós-graduação lato sensu em Audiodescrição, oferecida pela Universidade Federal de Juiz de Fora, nos anos de 2014 e 2015. Objetivou-se, no presente estudo, delinear o perfil das pesquisas produzidas na pós-graduação lato sensu em Audiodescrição, e de seus/suas participantes, buscando detectar relações entre a formação acadêmica/profissional e áreas de interesse e atuação. Considerando que a audiodescrição consiste em um recurso de acessibilidade comunicacional que possibilita a compreensão e a tradução de imagens em palavras, conforme preconiza a Lei Brasileira de Inclusão da Pessoa com Deficiência, tendo como público alvo os/as deficientes visuais; a pós-graduação, oferecida na modalidade presencial e a distância, possuía tanto o intuito de contribuir para a formação profissional, como de destacar a potencialidade da
\end{abstract}

\footnotetext{
* Doutora e mestra em Educação Física da Universidade Estadual de Campinas (UNICAMP). Pós-doutorado em Avaliação Educacional do Ensino pela Universidade Nacional do Ensino a distância - UNED-Espanha, financiado pela Fundacion Carolina. Pós-doutorado em Linguística, com ênfase em Análise de discurso da pela Universidade Estadual de Campinas (UNICAMP). Professora Associada do Departamento de Fundamentos da Educação Física da Faculdade de Educação Física e Desportos da Universidade Federal de Juiz de Fora (UFJF). Professora do Programa de Pós-Graduação em Educação da Universidade Federal de Juiz de Fora (UFJF). Líder do Núcleo de Pesquisa em Inclusão, Movimento e Ensino a Distância - NGIME/UFJF. Coordenadora cientifica da Asociación Latinoamaricana de Ciências del Deporte, Educación Física y Danza (ALCIDED). Representante do Brasil junto à International Association of Physical Education and Sport for Girls and Women (IAPESGW). Representante da América Latina na International Council of Sport Science and Phisycal Education (ICSSPE). E-mail: eliana.ferreira@ufjf.edu.br. Orcid: https://orcid.org/0000-0001-7978-8731

${ }^{* *}$ Doutoranda em Educação pela Universidade Federal de Juiz de Fora (UFJF). Membro do Grupo de Pesquisa: Relações entre a Filosofia e Educação para a Sexualidade na Contemporaneidade do Núcleo de Pesquisa em Inclusão, Movimento e Ensino a Distância - NGIME/UFJF. E-mail: gis-silva@bol.com.br. Orcid: https://orcid.org/0000-0001-9071-2818

*** Doutoranda em Educação pela Universidade Federal de Juiz de Fora (UFJF). Membro do Núcleo de Pesquisa em Inclusão, Movimento e Ensino a Distância - NGIME/UFJF. E-mail: janinelcarvalho@ gmail.com. Orcid: https://orcid.org/0000-0002-6562-8304

${ }^{* * * *}$ Mestranda em Educação pela Universidade Federal de Juiz de Fora (UFJF). Membro do Núcleo de Pesquisa em Inclusão, Movimento e Ensino a Distância - NGIME/UFJF. E-mail: thyaraduarte @hotmail.com. Orcid: https://orcid.org/0000-0003-0727-7232
} 
audiodescrição na promoção da inclusão das pessoas com deficiência na sociedade. Nessa perspectiva, os trabalhos de conclusão do curso mostram uma preocupação em promover essa inclusão, neles predominando temas relacionados a artefatos culturais como teatro, dança e arte cinematográfica.

PALAVRAS-CHAVE: Inclusão. Deficiência Visual. Audiodescrição. Formação. Artefatos Culturais

\begin{abstract}
The article on screen, conceived by the Nucleus of Research in Inclusion, Movement and Distance Learning - NGIME, was developed by analyzing the course completion papers presented as prerequisites for obtaining a postgraduate degree lato sensu in Audiodescription, offered by the Federal University of Juiz de Fora, in the years 2014 and 2015. The objective of this study was to delineate the profile of the research produced in the post-graduation lato sensu in Audiodescripción, and of its participants, seeking to detect relations between the academic / professional training and areas of interest and performance. Considering that audiodescription consists of a communicational accessibility feature that enables the comprehension and translation of images in words, as recommended by the Brazilian Law on the Inclusion of Persons with Disabilities, targeting the visually impaired; the postgraduate degree offered in the face and distance modality had both the aim of contributing to professional training and highlighting the potential of audio description in promoting the inclusion of people with disabilities in society. In this perspective, the work of conclusion of the course shows a concern to promote this inclusion, predominating themes related to cultural artifacts such as theater, dance and cinematographic art.
\end{abstract}

KEYWORDS: Inclusion. Visual Impairment. Audiodescription. Formation. Cultural Artifacts

\title{
Resumen
}

El artículo en pantalla, idealizado por el Núcleo de Investigación en Inclusión, Movimiento y Enseñanza a Distancia - NGIME, fue desarrollado mediante análisis de los trabajos de conclusión de curso presentados como requisitos previos para la obtención de título de postgrado lato sensu en Audiodescripción, ofrecida por la Universidad Federal de Juiz de Fora, en los años 2014 y 2015. Se objetivó, en el presente estudio, delinear el perfil de las investigaciones producidas en el postgrado lato sensu en Audiodescrición, y de sus participantes, buscando detectar relaciones entre la " formación académica / profesional y áreas de interés y actuación. Considerando que la audiodescripción consiste en un recurso de accesibilidad comunicacional que posibilita la comprensión y la traducción de imágenes en palabras, conforme preconiza la Ley Brasileña de Inclusión de la Persona con discapacidad, teniendo como público objetivo a los / las deficientes visuales; el postgrado, ofrecido en la modalidad presencial ya distancia, poseía tanto el propósito de contribuir a la formación profesional, como de destacar la potencialidad de la audiodescripción en la promoción de la inclusión de las personas con discapacidad en la sociedad. En esta perspectiva, los trabajos de conclusión del curso muestran una preocupación en promover esa inclusión, en ellos predominando temas relacionados a artefactos culturales como teatro, danza y arte cinematográfico.

PALABRAS CLAVE: Inclusión. Deficiencia Visual. Descripción de Audio. Entrenamiento. Artefactos Culturales

\section{INTRODUÇÃO}


A vigente pesquisa, concebida pelo Núcleo de Pesquisa em Inclusão, Movimento e Ensino a Distância - NGIME, objetivou realizar um levantamento das principais temáticas e discussões abordadas no desenvolvimento dos trabalhos de conclusão de curso vinculados à pós-graduação Lato Sensu em Audiodescrição, ofertada pela Universidade Federal de Juiz de Fora, no período de 2014 e 2015.

Pretendeu-se traçar o perfil das pesquisas produzidas, buscando, a partir da sintetização de ideias-chave e hierarquização das principais discussões e resultados, identificar relações entre formação acadêmica/profissional, capacitação e atuação. Destarte, foi realizada a leitura analítica e integral de 31 monografias ${ }^{2}$.

Para fins de organização do material incorporado, seguiu-se o reconhecimento de sete (7) dimensões de análise, a saber: onde a pesquisa foi realizada; formação dos autores; estratégia metodológica; tipo de delineamento de pesquisa; instrumentos de coleta de dados utilizados; descrição sumária da amostra; e principais temas estudados.

Este artigo constitui-se de três sessões, além desta introdução. A primeira traz uma discussão sobre a legislação referente à audiodescrição e a potencialidade desta como pesquisa e área de conhecimento, dividindo-se em três vertentes: Compromisso Social; Distribuição de Vagas e Saberes; e Perfil do Curso. A segunda sessão trata do perfil dos estudantes que cursaram a especialização em audiodescrição e os respectivos estudos. A última sessão contém as considerações finais, nas quais se faz uma reflexão sobre os resultados da análise e a repercussão da pesquisa.

\section{Audiodescrição: perfil e metodologia do curso Compromisso Social}

A audiodescrição (AD), modalidade de tradução audiovisual, é um recurso de acessibilidade comunicacional que visa assegurar o direito à inclusão social, cultural e educacional às pessoas com deficiência. Ocupa-se em descrever ações, expressões, linguagem corporal, lugares, vestimentas, ambientes, clima, cores, entre outros fatores que compõem nosso cotidiano e o cenário teatral, cinematográfico, televisivo, como também obras de arte visuais.

Em 03 de janeiro de 2015, passou a vigorar a Lei Brasileira de Inclusão - LBI (Lei no 13.146/2015), que, em seu artigo 42, incisos I e II, garantem à pessoa com deficiência o acesso ao esporte, ao turismo, ao lazer e a bens culturais, tais como programas televisivos, cinema, teatro e outras atividades culturais e desportivas em formato acessível. De acordo com os incisos I, II e III do artigo 67 da referida lei, os serviços de radiodifusão de sons e imagens devem viabilizar o uso da subtitulação por meio de legenda oculta; janela com intérprete da Libras; e audiodescrição.

Ciente da responsabilidade social na condição de referência no que tange à Educação Especial na perspectiva inclusiva, o NGIME assumiu, em parceria com a Coordenação de Acessibilidade Educacional, Física e Informacional - CAEFI - da Universidade Federal de

\footnotetext{
${ }^{2}$ O curso de pós-graduação lato sensu em Audiodescrição recebeu inicialmente cinquenta (50) matrículas, apresentando um percentual de $38 \%$ de evasão. Este artigo analisará as monografias apresentadas ao final da especialização, o que corresponde a $62 \%$ do número de matrículas do curso.
} 
Juiz de Fora - UFJF, em 2014, o compromisso de criar e ofertar o curso de pós-graduação lato sensu em Audiodescrição.

\section{Distribuição de vagas e saberes}

Considerando-se necessária a oferta de uma formação que contemplasse a legislação e preparasse os profissionais da educação e demais áreas para atuarem com propriedade conceitual nessa nova demanda, foram abertas cinquenta (50) vagas.

A divulgação da especialização ocorreu por meio de sites, jornais e e-mails, em todos os estados brasileiros, recebendo um total de 500 inscrições. O ingresso dos cursistas pautou-se na análise curricular dos candidatos, considerando-se as especificidades de cada região.

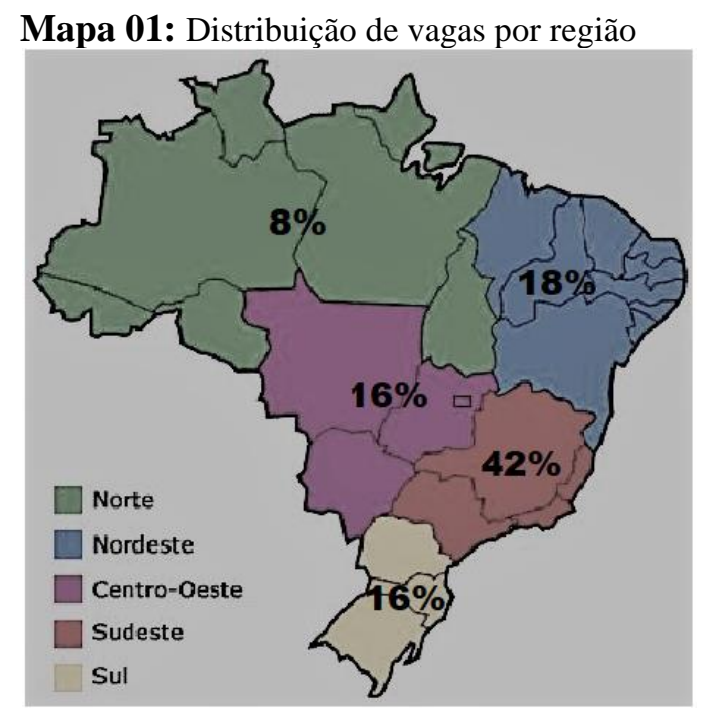

Inicialmente foram destinados $20 \%$ das vagas para cada região brasileira. No entanto, devido à maior demanda na região Sudeste e menor adesão nas demais, em especial na região Norte, houve um remanejamento de vagas. Assim, o curso de Audiodescrição iniciou suas atividades com vinte e um (21) representantes da região Sudeste; nove (9) alunos da região Nordeste; oito (8) estudantes da região Sul; oito (8) da região Centro-Oeste; e cinco (5) representantes da região Norte.

No entanto, o índice de evasão alcançou o marco de 38\%. Dessa maneira, o presente estudo concentra-se na análise de 31 monografias divididas entre quatro regiões, sendo cinco (5) representantes da região centro-oeste; seis (6) da região nordeste; sete (7) da região sul; e treze (13) da região sudeste. 
Mapa 02: Monografias por região

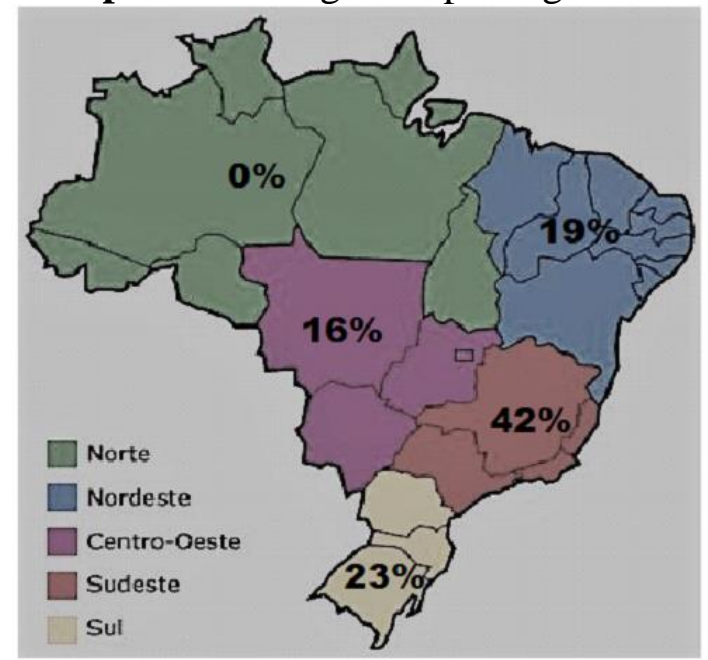

\section{Perfil do curso}

O curso, com carga horária total de 405 horas, foi estruturado de forma semipresencial, com aulas teóricas e práticas, tanto na modalidade presencial, como a distância. Os encontros presenciais aconteceram na UFJF, tendo sido conduzidos pela Coordenadora Pedagógica do projeto, com apoio da equipe docente, contabilizando 05 reuniões presenciais.

No decorrer da Especialização, foram ministradas 24 disciplinas, divididas em 5 módulos, como nos apresenta o quadro 01.

Quadro 01 Grade curricular do curso de pós-graduação lato sensu em Audiodescrição

\begin{tabular}{|l|c|c|c|c|}
\hline \multicolumn{1}{|c|}{ Grade curricular do curso de pós-graduação lato sensu em Audiodescrição } \\
\hline \multicolumn{1}{|c|}{ Disciplina } & \multicolumn{3}{|c|}{ Carga horária } & Módulo \\
\hline & Total & Presencial & EaD & I \\
\hline Metodologia de EaD & 15 & 15 & 0 & I \\
\hline Princípios da Acessibilidade públicas, legislação e & 15 & 0 & 15 & I \\
\hline $\begin{array}{l}\text { Políticas pessoas com } \\
\text { histórico }\end{array}$ & 30 & 0 & 15 & I \\
\hline $\begin{array}{l}\text { Inclusão cultural das públicos da } \\
\text { deficiência e os diferentes pú } \\
\text { audiodescrição }\end{array}$ & & & 30 & \\
\hline $\begin{array}{l}\text { Fundamentos e aspectos Linguísticos } \\
\text { da Audiodescrição }\end{array}$ & 30 & 0 & 30 & I \\
\hline Audiodescrição no cinema & 15 & 8 & 7 & II \\
\hline Linguagem cinematográfica & 15 & 0 & 15 & II \\
\hline Audiodescrição no teatro & 15 & 8 & 7 & II \\
\hline Linguagem teatral televisão e & 30 & 8 & 22 & II \\
\hline Audiodescrição na II \\
\hline
\end{tabular}

Educação e Fronteiras On-Line, Dourados/MS, v.10, n.28 p.55-64, jan./abr. 2020 


\begin{tabular}{|c|c|c|c|c|}
\hline linguagem televisiva & & & & \\
\hline História da Arte & 15 & 0 & 15 & III \\
\hline Descrição de Imagens Estáticas & 15 & 0 & 15 & III \\
\hline $\begin{array}{l}\text { Aplicação pedagógica e social da } \\
\text { audiodescrição }\end{array}$ & 15 & 0 & 15 & III \\
\hline $\begin{array}{l}\text { Audiodescrição em museus, espaços } \\
\text { culturais e ambientais }\end{array}$ & 15 & 8 & 7 & III \\
\hline $\begin{array}{l}\text { Audiodescrição em } \\
\text { corporativos e acadêmicos }\end{array}$ & 15 & 8 & 7 & III \\
\hline $\begin{array}{llcl}\text { Produção de } & \text { eventos } & \text { com } \\
\text { acessibilidade comunicacional } & \\
\end{array}$ & 15 & 8 & 7 & III \\
\hline Elaboração de roteiros & 15 & 0 & 15 & IV \\
\hline Metodologia do trabalho acadêmico & 15 & 0 & 15 & IV \\
\hline Pesquisa aplicada à audiodescrição & 15 & 0 & 15 & IV \\
\hline Recursos técnicos & 15 & 15 & 0 & IV \\
\hline Técnicas de locução & 15 & 15 & 0 & IV \\
\hline $\begin{array}{l}\text { Seminário de projeto da pesquisa } \\
\text { científica }\end{array}$ & 15 & 15 & 0 & IV \\
\hline $\begin{array}{l}\text { Orientação de trabalho de conclusão } \\
\text { de curso }\end{array}$ & 30 & 30 & 0 & $\mathrm{~V}$ \\
\hline
\end{tabular}

Em linhas gerais, todas as disciplinas ofertadas no curso de pós-graduação lato sensu em Audiodescrição destacaram a necessidade de entendimento e aprofundamento sobre a audiodescrição como potência sociocultural que possibilite melhorias na vida das pessoas com deficiência. Vislumbramos, assim, a importância de pesquisas e ofertas de cursos que abordem a audiodescrição, situando-a nos Estudos da Tradução, especificamente na área de tradução audiovisual.

Por esse pressuposto, a especialização, em análise neste estudo pautou-se na formação de audiodescritores preparados para atuar em diferentes demandas, aprimorando seu olhar, apreciação e compreensão.

[...] um audiodescritor é um observador ativo. É importante aprimorar seu letramento visual, olhar o mundo com maior acuidade a fim de compartilhar o que há nas imagens. O audiodescritor edita o que vê, ou seja, seleciona o que é mais importante para a compreensão e a apreciação de um evento. Parte do geral para o específico (ALVES; TELES; PEREIRA, 2011, p. 23).

Alves e Teixeira (2015) apontam que, para a elaboração de audiodescrição que corresponda às imposições legais trazidas na Lei $n^{\circ} 13.146 / 2015$, é necessária a obtenção de conhecimento quanto ao processo de produção de uma obra audiovisual e sobre a "construção de imagem, som, iluminação, pontos de vista, campo e contra-campo, enquadramento e planos" (ALVES; ARAÚJO, 2016, p.37).

Por esse viés, a Especialização em Audiodescrição idealizou em sua estrutura desenvolver estratégias para que os estudantes vivenciassem os procedimentos e recursos multissensoriais capazes de viabilizar o acesso físico, sensorial e atitudinal de pessoas com deficiência visual (cegueira e baixa visão) aos eventos corporativos e acadêmicos e espaços culturais, históricos, urbanos e de preservação ambiental; bem como de ampliar-lhes o conhecimento fílmico, teatral, televisivo e artístico. 


\section{Análise dos trabalhos produzidos: perfil dos/as estudantes e das monografias}

Devido à abrangência territorial da especialização em Audiodescrição ofertada pela UFJF, foram realizadas pesquisas em locais diversos, tais como: Oficina de Linguagem Cinematográfica, ofertada na Fundação Dorina Nowill para Cegos; Espetáculo Quincas, do Grupo Osfodidário, na cidade de João Pessoa; Centro de Apoio Pedagógico para Atendimento às Pessoas com Deficiência Visual (CAP) de Campo Grande - MS; Exposição: Diferentes e Iguais: Diversidade dos Povos Indígenas no Brasil; Centro Municipal de Educação dos Trabalhadores (CMET) Paulo Freire em Porto Alegre; Consultores de audiodescrição das regiões nordeste, sudeste e sul do Brasil; Centro de Apoio Pedagógico (CAP) - Centro Brasileiro de Reabilitação e Apoio ao Deficiente Visual (CEBRAV); Setor de Acessibilidade da Secretaria da Educação a Distância (SEDIS)/UFRN e no polo de EAD de Currais Novos/RN; Teatro Sesi - apresentação do espetáculo Rockincorpo; Colégio de Aplicação Universidade Federal do Maranhão (UFMA); escola CIADEVA (Centro de Integração e Apoio ao Deficiente Visual e Auditivo) em Taboão da Serra, no estado de SP; Instituto Benjamin Constant - Rio de Janeiro; TV Aparecida, localizada na cidade de Aparecida - SP; e Exposição "Sentir pra Ver", sediada no Memorial da Inclusão, em São Paulo.

$\mathrm{O}$ ingresso de estudantes de diferentes regiões possibilitou um olhar panorâmico referente às discussões e aplicabilidade da audiodescrição em território nacional. Durante a análise dos artigos, foi observada a distribuição dos autores segundo sua área de atuação, destacando-se a predominância de profissionais da área de Comunicação Social, Pedagogia e Educação Artística.

Gráfico 02: Perfil profissional dos/as estudantes

\section{Perfil profissional dos/as estudantes}

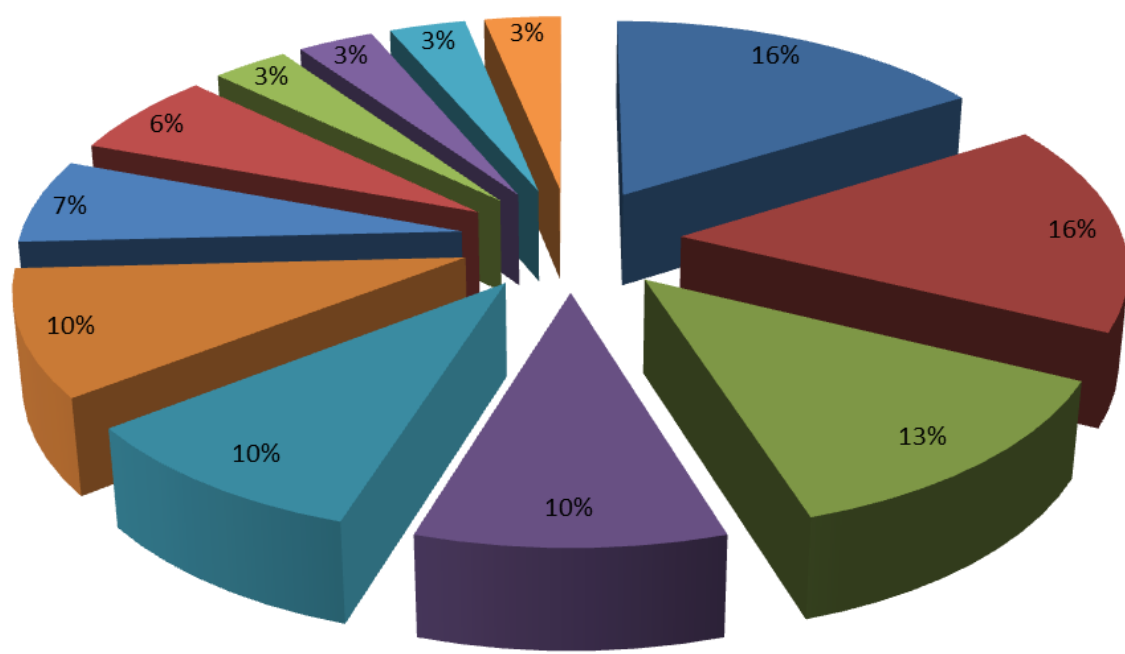

\footnotetext{
- Comunicação Social

- Pedagogia

- Educação Artística

- Educação Física

- Psicologia

- Letras

- Jornalismo

- Artes Cênicas

- Direito

- Ciências Biológicas

- Fonoudiologia

- História
} 
Dos trinta e um (31) autores/as, dezesseis (16) citaram nos artigos a sua inserção profissional na área de audiodescrição, arte, educação e acessibilidade. Três (3) pessoas são audiodescritoras, sendo dois (2) jornalistas e (1) formado em artes cênicas. Oito (8) trabalham na área de educação diretamente com pessoas com deficiência visual e/ou baixa visão, sendo três (3) pedagogos, dois (2) pedagogos e educadores físicos respectivamente, e um (1) formado em letras. Três (3) trabalham com arte, moda e teatro, sendo um (1) educador artístico, um (1) comunicador e um (1) fonoaudiólogo. Um (1) tradutor formado em letras e um (1) pedagogo que trabalha na produção de livro falado.

Vinte e dois (22) trabalhos utilizaram como abordagem metodológica a pesquisa qualitativa, três (3), a quali-quantitativa e um (1), a quantitativa; cinco (5) monografias não especificaram as abordagens metodológicas. Os tipos de pesquisa mais utilizados foram: descritiva - nove (9), descritiva-exploratória - seis (6), exploratória - cinco (5), estudo de caso - três (3), análise documental - duas (2), pesquisa ação - duas (2), cartografia - uma (1), e bibliográfica - uma (1). Não foi possível identificar os processos de pesquisa de três (3) produções.

Entre os instrumentos de coleta de dados mais utilizados, a entrevista foi adotada em nove (9) estudos, sete (7) fizeram análise de roteiro de audiodescrição, seis (6) valeram-se de questionário e quatro (4) utilizaram a criação de roteiros de audiodescrição. Os demais instrumentos foram: três (3) empregaram a observação; e análise de fontes fílmicas, observação informal, enquete, análise de obra de arte, uma (1) cada.

Em treze (13) trabalhos a pesquisa foi realizada com pessoas com deficiência visual ou baixa visão, as pesquisas foram realizadas com: alunos, professores, consultores e voluntários. Cinco (5) trabalhos realizaram pesquisa com professores que trabalham com alunos com deficiência visual ou baixa visão. Três (3) trabalhos fizeram pesquisa com audiodescritores.

Quanto ao conteúdo dos trabalhos, observou-se a abordagem de diversas temáticas, que foram agrupadas e descritas a partir de categorias importantes para este estudo. Os temas mais recorrentes foram: audiodescrição de artefatos culturais, dezenove (19), e audiodescrição e prática docente, sete (7).

Dentre os dezenove (19) trabalhos em que foram analisados artefatos culturais, Seis (6) trabalharam com a audiodescrição de filmes, séries e documentários, sendo um (1) no documentário "Boa Noite Solidão"; um (1) nos filmes "Chico Xavier", "Nosso Lar", "O palhaço", "Eu Receberia as Piores Notícias dos seus Lindos Lábios", "O Tempo e o Vento", "Simone" e "Praia do Futuro"; um (1) na série "Demolidor"; um (1) nos filmes "Madagascar 3: Os Procurados" e "Código de Honra"; um (1) no curta-metragem "Sob a Pele"; e um (1) na série "Mistérios no Convento".

Cada um de quatro (4) deles aprofundaram-se na audiodescrição de obra de arte das seguintes exposições: "Caixas Pretas sobre o cubo Branco", pertencente ao acervo do Grupo Amplexo - Recife; Exposição: Diferentes e Iguais: Diversidade dos Povos Indígenas no Brasil, do acervo do Centro Cultural Jesco Puttkamer da PUC Goiás; análise de uma das obras da exposição Hoy Toca el Prado, pertencente ao Museu Nacional do Prado em Madri; e Exposição "Sentir pra Ver", sediada no Memorial da Inclusão, em São Paulo.

Três (3) trabalharam com dança, respectivamente audiodescrição da dança em cadeira de roda; audiodescrição do espetáculo Rockincorpo: um espetáculo de dança contemporânea; e audiodescrição de espetáculos de pole dance. 
Um (1) fez a videoinstalação com audiodescrição do desfile da marca Desnudez Declamada. Um (1), oficina de linguagem cinematográfica. Um (1) criou o roteiro em audiodescrição de um roteiro da obra "A menina azul brilhante". Um (1) fez a audiodescrição de reportagem retirada do site do g1.com.br. Um (1) fez a audiodescrição de charges políticas. Um (1), audiodescrição de histórias em quadrinhos.

A predominância de trabalhos relacionados aos artefatos culturais, como cinema, teatro, espetáculos de dança, obras de artes, entre outras manifestações artísticas, justifica a necessidade de pesquisas nessa área, destacando os meandros para a formação do audiodescritor e para a implementação de audiodescrição de qualidade em espaços culturais.

As sete (7) pesquisas com o tema audiodescrição e prática docente foram realizadas nos seguintes locais, respectivamente: Centro de Apoio Pedagógico para Atendimento às Pessoas com Deficiência Visual (CAP) de Campo Grande - MS; Centro Municipal de Educação dos Trabalhadores (CMET) Paulo Freire em Porto Alegre; Centro de Apoio Pedagógico (CAP) - Centro Brasileiro de Reabilitação e Apoio ao Deficiente Visual (CEBRAV); Setor de Acessibilidade da Secretaria da Educação a Distância (SEDIS)/UFRN e no polo de EAD de Currais Novos/RN; um (1) Colégio de Aplicação Universidade Federal do Maranhão (UFMA); escola Centro de Integração e Apoio ao Deficiente Visual e Auditivo (CIADEVA) em Taboão da Serra no estado de SP; e Instituído Benjamin Constant - Rio de Janeiro.

\section{CONSIDERAÇÕES FINAIS}

O vigente artigo possui como intuito apresentar os resultados do mapeamento realizado para identificar o perfil dos audiodescritores formados na primeira pós-graduação lato sensu em Audiodescrição do Brasil, e de suas relativas produções científicas. Destacaram-se, assim, peculiaridades sobre o curso ofertado pelo NGIME, em parceria com a Coordenação de Acessibilidade Educacional, Física e Informacional - CAEFI - da Universidade Federal de Juiz de Fora - UFJF, tais como distribuição de vagas; vagas ocupadas; trabalhos concluídos; objetivos e metas da especialização; disciplinas; metodologia e estratégias de ensino; possibilitando diálogos fomentadores da construção de novas ofertas do curso, tanto pelo NGIME, como por outras instituições de ensino e núcleos de acessibilidade.

A pesquisa, de cunho quantitativo, traçou, estatisticamente, sete (7) dimensões de análise: local de realização da pesquisa; formação dos autores; estratégia metodológica; delineamento de pesquisa; instrumento de coleta de dados; descrição sumária da amostra e temas estudados.

Revelou, em seus resultados grande dimensão territorial no que tange ao lócus das pesquisas, tendo sido realizados estudos em João Pessoa, Campo Grande (MS), Porto Alegre, Currais Novos e em cidades do Maranhão e São Paulo. Quanto à formação dos autores, marcou a predominância de profissionais da área de Comunicação Social, Pedagogia e Educação Artística, No que concerne à estratégia metodológica, registrou maior adesão da abordagem qualitativa. Quanto ao delineamento de pesquisa, a descritiva predominou, bem como as entrevistas como instrumentos de coleta de dados. As pesquisas foram realizadas, majoritariamente, com pessoas com deficiência visual ou baixa visão, e, com referência ao 
conteúdo dos trabalhos houve uma prevalência de pesquisas relacionadas à audiodescrição e artefatos culturais.

Diante do exposto, pode-se concluir que é possível propiciar visibilidade para a audiodescrição e viabilidade para cursos sobre essa temática, contribuindo para a expansão dos conhecimentos quanto ao processo de produção de uma obra audiovisual e, para a formação de profissionais capacitados e preparados para promoverem a acessibilidade e inclusão de pessoas com deficiência nos diversos setores de nossa sociedade.

\section{REFERÊNCIAS}

ALVES, Soraya Ferreira; ARAÚJO, Vera Lúcia Santiago. Formação do audiodescritor: A estética cinematográfica como base para o aprendizado da estética da audiodescrição. Materiais, Métodos e Produtos. Cad. Trad., Florianópolis, v.36, n.3, p.34-59, set.-dez./2016.

ALVES, Soraya F.; TEIXEIRA, Charles R. Audiodescrição para pessoas com deficiência visual: princípios sociais, técnicos e estéticos. In SANTOS, Cynthia; BESSA, Cristiane R.; LAMBERTI, Flávia (Org.). Tradução em Contextos Especializados. Brasília: Editora Verdana, 2015.

ALVES, Soraya F.; TELES, Veryanne C.; PEREIRA, Tomás V. Propostas para um modelo brasileiro de audiodescrição para deficientes visuais. In: Revista Tradução e Comunicação. N. 22, 2011. Disponível em: http://sare.unianhanguera. edu.br/index.php/rtcom/article/view/3158. Acesso em: <15 maio de 2018>.

FERREIRA, Eliana Lúcia. Princípios dos recursos de acessibilidade: a audiodescrição/Eliana Lúcia Ferreira. Juiz de Fora-MG: NGIME/UFJF, 2017.

Recebido em: 03/10/2019

Aprovado em: 05/12/2019 